\title{
Estimation of Hourly Global Solar Radiation for Composite Climate
}

\author{
M. Jamil Ahmad and G.N. Tiwari*
}

Center for Energy Studies, Indian Institute of Technology, Hauz Khas, New Delhi 110016, India

\begin{abstract}
In this communication, an attempt has been made to estimate hourly global solar radiation for the composite climate of New Delhi (latitude: $28.58^{\circ} \mathrm{N}$, longitude: $77.20^{\circ} \mathrm{E}$, elevation: $216 \mathrm{~m}$ above mean sea level) using regression analysis based on the model proposed by Al-Sadah et al. (1990). More than 39000 data of hourly solar radiation on a horizontal surface measured at New Delhi were compared with hourly data calculated by various calculation models. Comparison between estimated and measured values shows that the constants derived for New Delhi provide good estimates of the hourly global radiation except for the morning and evening hours. The present results are comparable with the Liu and Jordan (1960) and Collares-Pereira and Rabl (1979) models which also correlate hourly values and daily totals of the global radiation.
\end{abstract}

Keywords: Hourly global radiation, New Delhi, composite climate.

\section{INTRODUCTION}

The design of any solar energy system requires knowledge of the availability of solar radiation data at the location of interest. The average distribution of solar radiation over the day is of fundamental importance in many areas of solar energy. It provides the basis for predicting instantaneous solar radiation from the commonly available monthly averages of daily insolation. For locations where measured data are not available, empirical correlations developed by various investigators can be used to estimate the solar radiation.

Sometimes the design of solar energy devices needs accurate estimations of hourly solar radiation values. At places where hourly radiation values are not available, it has to be estimated from the daily values. There are various methods which allow the conversion of daily solar radiation into hourly values. The distribution of total radiation on a horizontal surface over a day was examined by Liu and Jordan [1], who showed that the ratio of hourly to daily radiation could be correlated with the local day length and hour angle. The hours were designated by the time for the mid point of the hour, and the days were considered to be symmetrical about solar noon. The results of Liu and Jordan were confirmed by Collares-Pereira and Rabl [2], using a wider database. A model for hourly solar radiation has also been developed by Al-Sadah et al. [3], which is correlated with the local time of day. There are some other models $[4,5]$ to estimate the hourly solar radiation. Singh and Tiwari has evaluated cloudiness factor and atmospheric transmittance for composite climate of New Delhi [6]. Cucumo et al. carried out experimental testing of models for the estimation of hourly solar radiation on vertical surfaces at Arcavacata di Rende [7]. As the availability of solar radiation for a place depends upon the climatic conditions of the locality, a corre-

*Address correspondence to this author at the Center for Energy Studies, Indian Institute of Technology, Hauz Khas, New Delhi 110016, India;

E-mail: gntiwari@ces.iitd.ac.in lation for a place may not be suitable for other places of different climatic conditions.

The purpose of this paper is to present an analysis of hourly solar radiation data and to develop new regression constants for estimating the hourly global solar radiation on a horizontal surface, which is based on the solar model proposed by Al-Sadah et al. [3]. The analysis has been done for the following weather conditions.

i). Clear day (blue sky): If diffuse radiation is less than or equal to $25 \%$ of global radiation and sunshine hour is more than or equal to 9 hours.

ii). Hazy day (fully): If diffuse radiation is less than $50 \%$ or more than $25 \%$ of global radiation and sunshine hour is between 7 to 9 hours.

iii). Hazy and cloudy (partially): If diffuse radiation is less than $75 \%$ or more than $50 \%$ of global radiation and sunshine hour is between 5 to 7 hours.

iv). Cloudy day (fully): If diffuse radiation is more than $75 \%$ of global radiation and sunshine hour is less than 5 hours.

The above four conditions constitute the composite climate of New Delhi.

The present results are compared to the data obtained from India Meteorology Department (IMD) Pune, India. And the predictions from Liu and Jordan [1] and Collares-Pereira and Rabl [2] methods.

\section{Meteorological Data}

The solar radiation data comprising of monthly mean hourly global solar radiation for New Delhi (latitude: $28.58^{\circ}$ $\mathrm{N}$, longitude: $77.20^{\circ} \mathrm{E}$, elevation: $216 \mathrm{~m}$ above mean sea level) have been collected for the period of 1991-2001 from India Meteorology Department (IMD) Pune, India. These data have been obtained using a thermoelectric pyranometer. The pyranometer used are calibrated once a year with refer- 
ence to the World Radiometric Reference (WRR). The estimated uncertainty in the measured data is about $\pm 5 \%$ [6].

\section{Mathematical Models}

Liu and Jordan [1] proposed the following correlation to estimate the monthly mean hourly global radiation on a horizontal surface $(\bar{I})$ from the monthly mean daily global radiation $(\bar{H})$ on a horizontal surface.

$$
\frac{\bar{I}}{\bar{H}}=\frac{\pi}{24} \frac{\cos w-\cos w_{s}}{\sin w_{s}-\frac{\pi w_{s}}{180} \cos w_{s}}
$$

Where $\mathrm{w}$ is the hour angle in degrees for the midpoint of the hour for which the calculation is to be made, and $\mathrm{w}_{\mathrm{s}}$ is the sunset hour angle which is expressed by.

$w_{s}=\cos ^{-1}(-\tan \phi \tan \delta)$ and

$\delta=23.45 \sin \left[\left(\frac{360}{365}\right)(284+n)\right]$

To estimate the monthly mean hourly radiation on a horizontal surface, Collares-Pereira and Rabl [2] proposed the following correlation.

$$
\frac{\bar{I}}{\bar{H}}=(a+b \cos w) \frac{\pi}{24} \frac{\cos w-\cos w_{s}}{\sin w_{s}-\frac{\pi w_{s}}{180} \cos w_{s}}
$$

The coefficients $\mathrm{a}$ and $\mathrm{b}$ are given by

$a=0.409+0.5016 \sin \left(w_{s}-60\right)$

$b=0.6609-0.4767 \sin \left(w_{s}-60\right)$

Al-Sadah et al. [3] developed the following correlation to estimate the ratio of the monthly mean hourly $(\bar{I})$ to monthly mean daily $(\bar{H})$ global radiation on a horizontal surface.

$\bar{I} / \bar{H}=a_{1} t^{2}+b_{1} t+c_{1}$

for $\quad 6.00 \leq t \leq 18.00$

hours

where $\mathrm{t}$ is local time in

The coefficient of correlation I was calculated using the formula defined as

$$
r=\frac{N\left(\sum X_{\text {exp }} \cdot X_{\text {pre }}\right)-\left(\sum X_{\text {exp }}\right) \cdot\left(\sum X_{\text {pre }}\right)}{\sqrt{N \cdot\left(\sum X_{\text {exp }}^{2}\right)-\left(\sum X_{\text {exp }}\right)^{2}} \sqrt{N \cdot\left(\sum X_{\text {pre }}^{2}\right)-\left(\sum X_{p r e}\right)^{2}}}
$$

\section{Methodology}

The solar radiation data comprising of monthly mean hourly global solar radiation for New Delhi have been collected for the period of 1991-2001 from India Meteorology Department (IMD) Pune, India. Eleven years data (over 39000) were divided into twelve sets, each set comprising data of each month. Thus eleven years data of each month were studied separately. Depending upon sunshine hours and ratio of diffuse to global radiation, each month data (of 1 years) were subdivided into four subsets for four different weather types i.e. 'a', 'b', 'c' and 'd'. These weather types have already been defined which constitute the composite climate of New Delhi. Then the monthly mean hourly global radiation for each type of weather was calculated. Similarly the monthly mean daily global radiation for each type of weather was calculated. Thus the ratio of monthly mean hourly global radiation to monthly mean daily global radiation was calculated for each type of weather.

To calculate the ratio of monthly mean hourly global radiation to monthly mean daily global radiation using Liu and Jordan model, a computer program was developed in Matlab. The input parameter for $w$ was local time in hours from 8 to 17 and for $w_{s}$ the input parameter were $\phi$ and $n$.

To calculate the ratio of monthly mean hourly global radiation to monthly mean daily global radiation using Collares-Pereira and Rabl, again a computer program was developed in Matlab. The input parameter was same as in Liu and Jordan model.

The new constants were determined from regression analysis between measured ratio (monthly mean hourly to daily global radiation) versus local time.

\section{Results and Discussion}

Least squares regression analysis was used to fit equation (3) to the data for each hour of the day to obtain the values of the regression constants $a_{1}, b_{1}$ and $c_{1}$ for each month of the year. The regression constants $a_{1}, b_{1}$ and $c_{1}$ for each month of the year are given in the Tables 1-4 for weather types ' $a$ ', 'b', 'c' and ' $d$ ' respectively. Verification of the present constants was made by comparing the estimated ratios of hourly to daily global radiation with the measured values. The estimated values of the monthly mean ratios, along with the measured values, as a function of the local time $t$ for the months of January and June (for four different weather types) are plotted in Figs. (1a-d) and (2a-d).

Table 1. New Constants $a_{1}, b_{1}$ and $c_{1}$ for ' $a$ ' Type Weather

\begin{tabular}{|l|c|c|c|}
\hline \multicolumn{4}{|c|}{ New Constants } \\
\hline & $\mathbf{a}_{\mathbf{1}}$ & $\mathbf{b}_{\mathbf{1}}$ & $\mathbf{c}_{\mathbf{1}}$ \\
\hline \hline January & -0.0065 & 0.16 & -0.84 \\
\hline February & -0.0057 & 0.14 & -0.75 \\
\hline March & -0.0049 & 0.12 & -0.62 \\
\hline April & -0.0042 & 0.1 & -0.51 \\
\hline May & -0.0039 & 0.098 & -0.48 \\
\hline June & -0.0036 & 0.088 & -0.42 \\
\hline July & -0.0038 & 0.095 & -0.46 \\
\hline August & -0.0042 & 0.1 & -0.51 \\
\hline September & -0.0047 & 0.12 & -0.6 \\
\hline October & -0.0059 & 0.15 & -0.78 \\
\hline November & -0.0066 & 0.16 & -0.86 \\
\hline December & -0.0069 & 0.17 & -0.91 \\
\hline
\end{tabular}


Table 2. New Constants $a_{1}, b_{1}$ and $c_{1}$ for ' $b$ ' Type Weather

\begin{tabular}{|l|c|c|c|}
\hline \multicolumn{4}{|c|}{ New Constants } \\
\hline & $\mathbf{a}_{\mathbf{1}}$ & $\mathbf{b}_{\mathbf{1}}$ & $\mathbf{c}_{\mathbf{1}}$ \\
\hline \hline January & -0.0065 & 0.16 & -0.86 \\
\hline February & -0.0057 & 0.14 & -0.74 \\
\hline March & -0.0049 & 0.12 & -0.62 \\
\hline April & -0.0042 & 0.1 & -0.51 \\
\hline May & -0.0039 & 0.095 & -0.45 \\
\hline June & -0.0037 & 0.093 & -0.45 \\
\hline July & -0.0039 & 0.096 & -0.47 \\
\hline August & -0.0041 & 0.1 & -0.5 \\
\hline September & -0.0048 & 0.12 & -0.6 \\
\hline October & -0.0055 & 0.13 & -0.66 \\
\hline November & -0.0061 & 0.15 & -0.76 \\
\hline December & -0.0072 & 0.18 & -0.94 \\
\hline
\end{tabular}

Table 3. New constants $a_{1}, b_{1}$ and $c_{1}$ for ' $c$ ' Type Weather

\begin{tabular}{|l|c|c|c|}
\hline \multicolumn{4}{|c|}{ New Constants } \\
\hline & $\mathbf{a}_{\mathbf{1}}$ & $\mathbf{b}_{\mathbf{1}}$ & $\mathbf{c}_{\mathbf{1}}$ \\
\hline \hline January & -0.007 & 0.18 & -0.95 \\
\hline February & -0.0056 & 0.14 & -0.74 \\
\hline March & -0.0053 & 0.13 & -0.68 \\
\hline April & -0.0047 & 0.12 & -0.58 \\
\hline May & -0.0041 & 0.1 & -0.49 \\
\hline June & -0.0042 & 0.11 & -0.55 \\
\hline July & -0.0039 & 0.097 & -0.46 \\
\hline August & -0.0044 & 0.11 & -0.56 \\
\hline September & -0.0051 & 0.13 & -0.66 \\
\hline October & -0.006 & 0.15 & -0.78 \\
\hline November & -0.0069 & 0.17 & -0.93 \\
\hline December & -0.0071 & 0.18 & -0.94 \\
\hline
\end{tabular}

Table 4. New Constants $a_{1}, b_{1}$ and $c_{1}$ for ' $d$ ' Type Weather

\begin{tabular}{|l|c|c|c|}
\hline \multicolumn{4}{|c|}{ New Constants } \\
\hline & $\mathbf{a}_{\mathbf{1}}$ & $\mathbf{b}_{\mathbf{1}}$ & $\mathbf{c}_{\mathbf{1}}$ \\
\hline \hline January & -0.0068 & 0.17 & -0.9 \\
\hline February & -0.006 & 0.15 & -0.78 \\
\hline March & -0.005 & 0.13 & -0.64 \\
\hline April & -0.0043 & 0.11 & -0.53 \\
\hline May & -0.0041 & 0.1 & -0.5 \\
\hline June & -0.0039 & 0.096 & -0.46 \\
\hline July & -0.004 & 0.098 & -0.47 \\
\hline August & -0.0038 & 0.094 & -0.45 \\
\hline September & -0.0045 & 0.11 & -0.56 \\
\hline October & -0.0059 & 0.14 & -0.71 \\
\hline November & -0.0068 & 0.17 & -0.9 \\
\hline December & -0.0072 & 0.18 & -0.96 \\
\hline
\end{tabular}

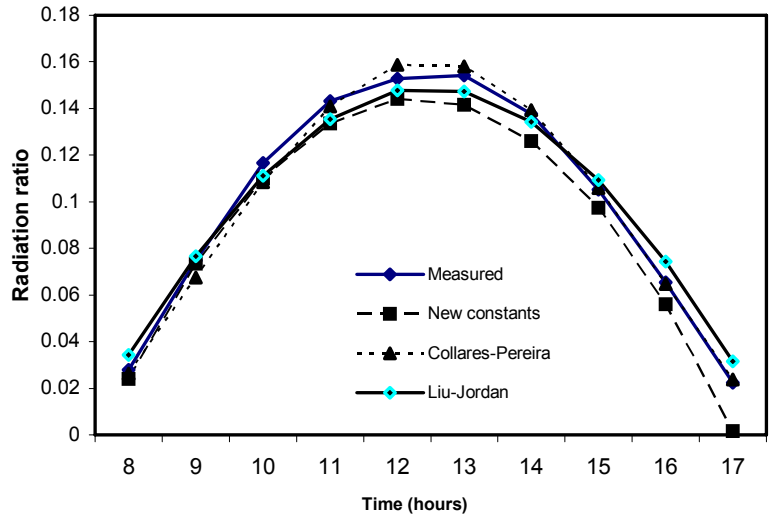

Fig (1a). Measured and estimated ratios of monthly mean hourly to daily global radiation for the month of January ('a' type weather).

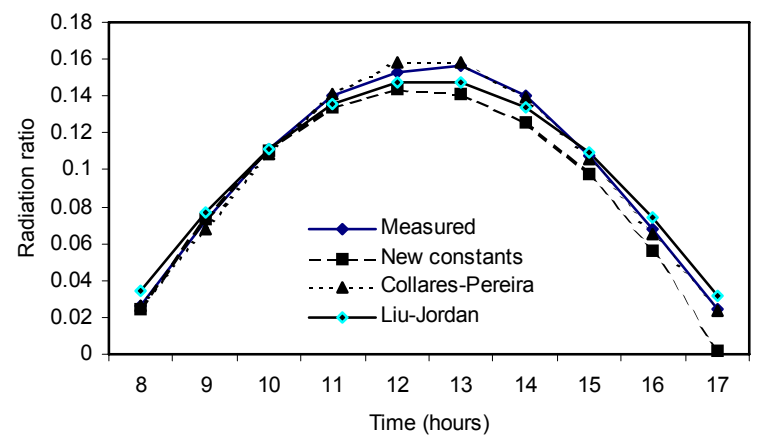

Fig. (1b). Measured and estimated ratios of monthly mean hourly to daily global radiation for the month of January ('b' type weather).

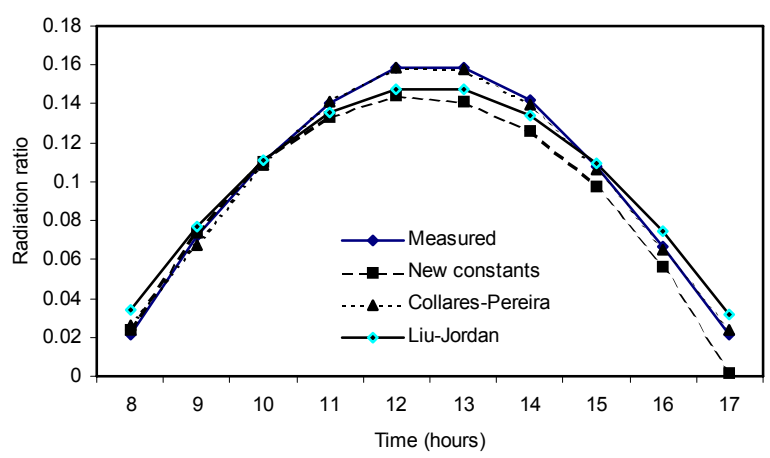

Fig. (1c). Measured and estimated ratios of monthly mean hourly to daily global radiation for the month of January ('c' type weather).

A close agreement has been observed between the measured and theoretical values of the hourly global radiation. The agreement is more pronounced between 9.00 and 15.00 hours. A significant deviation in the estimated values has been observed at low sun angles (morning and evening hours), which is of little consequence for solar energy operated systems, because the global radiation during morning 
and evening hours is very small and constitutes only a small part of the radiation for the day. The present results are also compared with the theoretical estimates of Liu and Jordan [1] and Collares-Pereira and Rabl [2]. The comparison shows that the present constants produce comparative results to the predictions of the Liu and Jordan and Collares-Pereira and Rabl models.

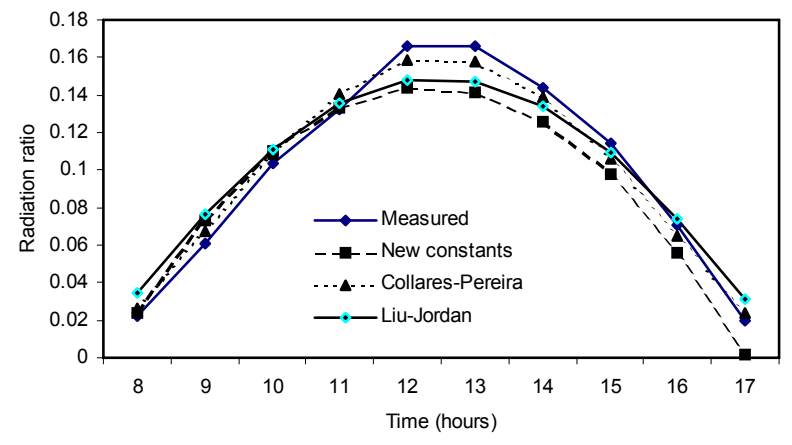

Fig. (1d). Measured and estimated ratios of monthly mean hourly to daily global radiation for the month of January ('d' type weather).

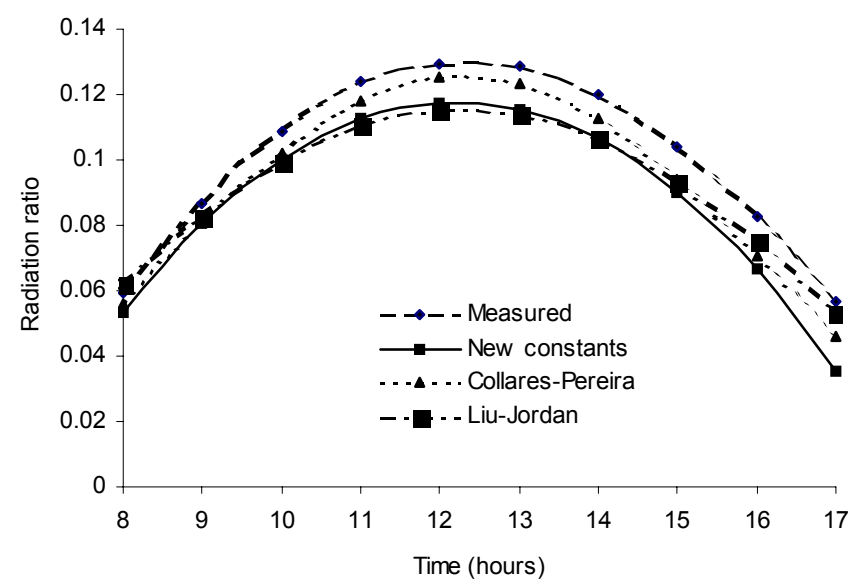

Fig. (2a). Measured and estimated ratios of monthly mean hourly to daily global radiation for the month of June ('a' type weather).

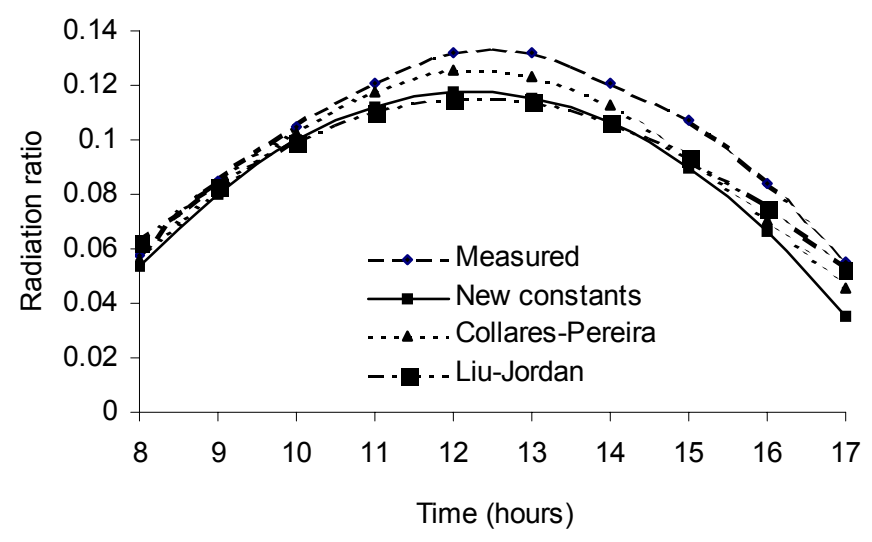

Fig. (2b). Measured and estimated ratios of monthly mean hourly to daily global radiation for the month of June ('b' type weather).

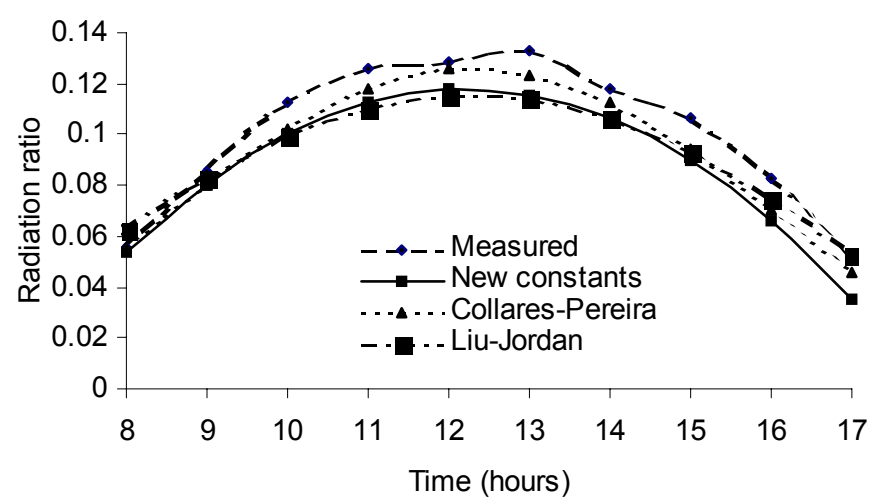

Fig. (2c). Measured and estimated ratios of monthly mean hourly to daily global radiation for the month of June ('c' type weather).

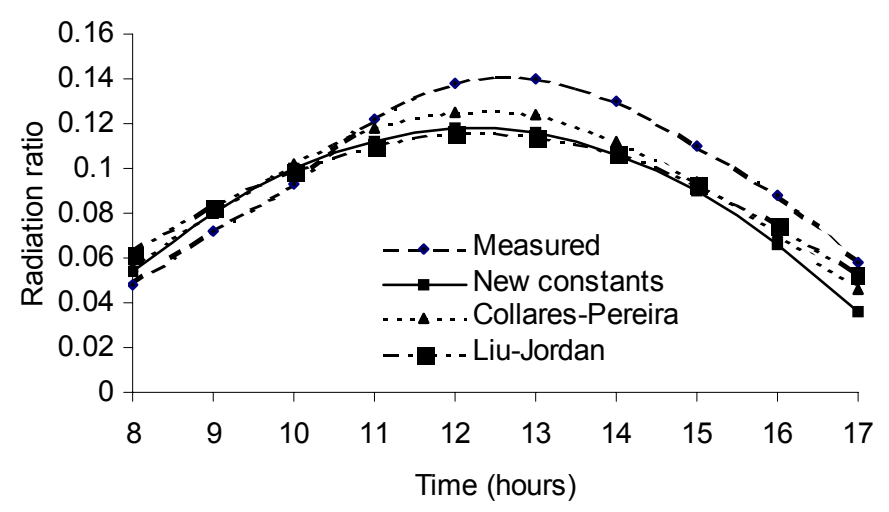

Fig. (2d). Measured and estimated ratios of monthly mean hourly to daily global radiation for the month of June ('d' type weather).

The coefficient of correlation for each month and for all four weather types has been calculated but to avoid repetition, its values are shown only for ' $a$ ' type weather. Table $\mathbf{5}$ shows that the performance of the proposed model is less effective particularly in April and in August comparing with the Liu and Jordan model and the Collares-Pereira and Rabl model in terms of coefficient of correlation. April month is a transition period from winter to summer and August is a transition period from monsoon to winter. Transition period may be a reason for less effectiveness of the proposed model in April and August.

From Figs. $(\mathbf{1 , 2})$ and Table 5 it is clear that all the three models can comfortably be employed to estimate the hourly global solar radiation for the composite climate of New Delhi within the accuracy limit of $10 \%$.

\section{CONCLUSIONS}

The hourly global radiation on a horizontal surface can be satisfactorily estimated for the composite climate of New Delhi by using the new regression constants. A comparison of the present results with existing measurements shows that the estimated and measured values are in close agreement, except for low sun angles. The agreement is more pronounced for the peak radiation hours. The present constants produce comparable results to the predictions of the Liu and Jordan and Collares-Pereira and Rabl models. 
Table 5. Coefficient of Correlation for ' $a$ ' Type Weather

\begin{tabular}{|l|c|c|c|}
\hline & $\begin{array}{c}\text { New } \\
\text { Constants }\end{array}$ & $\begin{array}{c}\text { Liu and } \\
\text { Jordan }\end{array}$ & $\begin{array}{c}\text { Collares-Pereira } \\
\text { and Rabl }\end{array}$ \\
\hline \hline January & 0.9889 & 0.9929 & 0.9958 \\
\hline February & 0.9722 & 0.9942 & 0.997 \\
\hline March & 0.9285 & 0.9716 & 0.9806 \\
\hline April & 0.8446 & 0.9881 & 0.9896 \\
\hline May & 0.9878 & 0.9824 & 0.9815 \\
\hline June & 0.9723 & 0.9902 & 0.9905 \\
\hline July & 0.9973 & 0.9858 & 0.9911 \\
\hline August & 0.8686 & 0.9922 & 0.9925 \\
\hline September & 0.9406 & 0.9761 & 0.9738 \\
\hline October & 0.9601 & 0.9293 & 0.9182 \\
\hline November & 0.9492 & 0.9483 & 0.9384 \\
\hline December & 0.9859 & 0.9712 & 0.9659 \\
\hline
\end{tabular}

All the three models can satisfactorily be employed to estimate the hourly global solar radiation for the composite climate of New Delhi within the accuracy limit of $10 \%$.

\section{ABBREVIATIONS}

$\bar{I} \quad=$ Monthly mean hourly global radiation on a horizontal surface, $\mathrm{W} / \mathrm{m}^{2}$

$\bar{H} \quad=$ Monthly mean daily global radiation on a horizontal surface, $\mathrm{W} / \mathrm{m}^{2}$ $\mathrm{w}=$ Hour angle in degrees for the midpoint of the hour

$\mathrm{w}_{\mathrm{s}} \quad=\quad$ Sunset hour angle

$\phi \quad=$ Latitude of the location in degree

$\delta=$ Declination angle in degree

$n \quad=$ Nth day of the year i.e. 1 for first January

$\mathrm{t}=$ Local time in hours

$r \quad=$ Coefficient of correlation

$\mathrm{N} \quad=$ Number of data

$\mathrm{Xexp}=$ Measured (experimental) value of variable $\mathrm{X}$

Xpre $=$ Predicted value of variable $\mathrm{X}$

\section{REFERENCES}

[1] Liu BYH, Jordan RC. The interrelationship and characteristic distribution of direct, diffuse and total solar radiation. Solar Energy 1960; 4: 1-19.

[2] Collares-Pereira M, Rabl A. The average distribution of solar radiation correlation between diffuse and hemispherical and between daily and hourly insolation values. Solar Energy 1979; 22: 155164.

[3] Al-Sadah FH, Ragab FM, Arshad MK. Hourly solar radiation over Bahrain. Energy 1990; 15(S): 395.

[4] Bird R, Riordan C. Simple solar spectral model for direct and diffuse irradiance on horizontal and tilted planes at the earth's surface for cloudless atmospheres. U.S. Solar Energy Research Institute Technical Report.1984. TR-215-2436; Golden, Colorado.

[5] Justus C L, Paris V. A model for solar irradiance and radiance at the bottom and top of a cloudless atmosphere. J Clim App Meteor 1985; 24: 193-205.

[6] Singh HN, Tiwari GN. Evaluation of cloudiness / haziness factor for composite climate. Energy 2005; 30: 1589-1601.

[7] Cucumo M, Rosa ADe, Ferraro V, Kaliakatsos D, Marinelli V. Experimental testing of models for the estimation of hourly solar radiation on vertical surfaces at Rende. Arcavacata di Solar Energy 2007; 81: 692-695.

This is an open access article distributed under the terms of the Creative Commons Attribution License (http://creativecommons.org/licenses/by/2.5/), which permits unrestrictive use, distribution, and reproduction in any medium, provided the original work is properly cited. 